\title{
Tendencies of Reproduction Processes in Regional Context
}

\author{
Simbul Akhmetova ${ }^{1}$, Riyaz Minzaripov ${ }^{1}$, Farida Ishkineeva ${ }^{1} \&$ Guzel Ishkineeva $^{1}$ \\ ${ }^{1}$ Kazan Federal University, Kazan, Russia \\ Correspondance: Farida Ishkineeva, Institute of Socio-Philosophic Sciences and Mass Communications, 18, \\ Kremlyovskaya St., 420008, Kazan, Republic of Tatarstan, Russia. Tel: 7-843-233-7841. E-mail: \\ farida1967@mail.ru
}

\author{
Received: September 22, 2014 Accepted: September 30, 2014 Online Published: December 2, 2014 \\ doi:10.5539/ass.v11n1p225 \\ URL: http://dx.doi.org/10.5539/ass.v11n1p225
}

\begin{abstract}
Reproduction processes in the Republic of Tatarstan which is perceived as one of the most dynamically developing regions of Russia are analyzed in this article on the basis of statistical data. The comparative strategy is used in the research, such as the following: the data of the modern demographic situation is compared to the data of the demographic situation at the beginning of XXI century. The final aim is to find out for the tendencies of the development of regional community, their specifics, degree of correlation with Russian demographic development.
\end{abstract}

Keywords: demographic processes, region problems, mortality, birth rate, demographic potential, population loss, population replacement level

\section{Introduction}

Demographic situation in Russia in the past two decades is characterized by depopulation, such as the following: from the middle of 1990-es to the middle of 2000-es average annual natural population loss was near 850000 of people. From the beginning of 2000 -es the number of born is progressively increasing and the number of death is progressively decreasing, however, the birth rate is still low, and death rate is rather high ("European birth rate and African death rate" on behalf of one of the Russian researches of this problem) (Bessarabova, 2013). Overall population growth in 313000 people was registered in 2012, including 5000 people of natural population growth and 308000 of migration population growth (Russian Demography, 2013). However different regions of Russian Federation have their own specificities, such as the following: the stabilization of demographic processes is taking place in the prosperous regions and continuous crisis is taking place in lagging regions. The Republic of Tatarstan (Note 1) is perceived as one of the most dynamic and favorable regions of Russian Federation in terms of economical, social and demographic development. Information of resolving of demographical crisis is transmitted to the Tatarstan community in the past 2-3 years in the following way, such as: presenting of statistical data of increasing of fertility in particular cities and rural areas, the beginning of birth-rate decreasing, and natural population growth (Statistical bulletin, 2012). Our aim is to find out whether there are grounds for the optimism, whether there are changes in reproduction processes on the regional level and what is character of these changes, whether population policy methods inputted in every-day life are really effective, and what is the overall image of the Tatarstan citizen at the beginning of XXI century?

\section{Materials and Methods}

The main information source is statistical data placed on official web-site of Federal Service for National Statistics, Regional Service for National Statistics, and the Final results of All-Russian population census 2010. The comparative method will be used to describe the situation in region, so current data will be compared to the following data 10 years ago; regional reproduction results will be compared to Russian tendencies.

\section{Discussion}

The Republic of Tatarstan is one of the biggest regions for population in Volga Federal District (second after the Republic of Bashkortostan), and it is the only region where the population increase. The increase of the population registered at the period from 2002 to 2010 years was due to migration in the beginning (Tatcenter, 2013), and due to the natural population growth from 2011 (Russian Demography, 2013). This indicates favorable situation in the republic. Information about the movement of urban and city population in the Republic of Tatarstan can be found in the Table 1 (Statistical Bulletin, 2008, 2013). 
Table 1. Population of the Republic of Tatarstan, in dynamics (for the begging of the year)

\begin{tabular}{cccccc}
\hline \multirow{2}{*}{ Years } & Total number of population, & \multicolumn{2}{c}{ Among them, thousands of people } & \multicolumn{2}{c}{ Among them, \% } \\
\cline { 3 - 6 } & thousands of people & urban & rural & urban & rural \\
\hline 2002 & 3781,9 & 2790,7 & 991,2 & 73,8 & 26,2 \\
2003 & 3777,7 & 2791,0 & 986,7 & 73,9 & 26,1 \\
2004 & 3772,9 & 2793,7 & 979,2 & 74,0 & 26,0 \\
2005 & 3768,5 & 2806,8 & 961,7 & 74,5 & 25,5 \\
2006 & 3761,5 & 2803,9 & 957,6 & 74,5 & 25,5 \\
2007 & 3760,5 & 2806,2 & 954,3 & 74,6 & 25,4 \\
2008 & 3762,8 & 2811,0 & 951,8 & 74,7 & 25,3 \\
2009 & 3773,5 & 2831,7 & 941,8 & 75,0 & 25,0 \\
2010 & 3784,5 & 2845,2 & 939,3 & 75,2 & 24,8 \\
2011 & 3787,5 & 2856,4 & 931,1 & 75,4 & 24,6 \\
2012 & 3803,2 & 2878,3 & 924,9 & 75,7 & 24,3 \\
2013 & 3822,9 & 2901,7 & 921,2 & 75,9 & 24,1 \\
\hline
\end{tabular}

It is demonstrated in the table that the number of population in the Republic of Tatarstan was decreasing from 2002 to 2008, and it started to increase from 2008 till now, and the number of population registered in 2010 has surpassed the number in 2002. If we compare the data of 2002 and 2013 we can notice that the population increased on 41 thousand people which is $1,1 \%$ to the data registered in 2002. The number of population has significantly increased in 2012 (on 19,7 thousand people). It is worth mentioning that during financial crisis in 2009-2010 the number of population was still increasing. So, there is a tendency for increase of population with follow-up redistribution with the increase of urban and loss of rural population in the studied period of time.

At the same time, the population of the Republic of Tatarstan is getting older as well as the whole Russia, so the average age of the population of the republic in 2010 is 38.6 years, Russian Federation - 39 years, in 2002 the inhabitants of Tatarstan and Russia were younger so it was -37.1 and 37.7 years respectively. The pace of population ageing is less intense in Tatarstan than in Russia. At the same time, the ageing is feminizing, so among the oldest people of the republic (those over 90 years) there is five times more women than men. There more women long liver in the city (five times more than men) as well as in the village (seven times more than men). The gender imbalance remains, at the same time the sex ratio has changed, so there was 1000 men for 1661 women in 2002, and 1000 men for 1166 women in 2010. Tatarstan increasingly urbanizing (currently, $75.4 \%$ of the urban population, the city residents growth was $2.3 \%$ - compared to 2002). Tatarstan is becoming more literate (there were 144 people to 1000 people with high education in 2002, and 224 to 1000 in 2010). Tatarstan is becoming more multiethnic and multilingual (there appear other nations in addition to the Tatars and Russian), that is caused by the intensification of migration from countries near and far abroad (The final results of All-Russian population census, 2013).

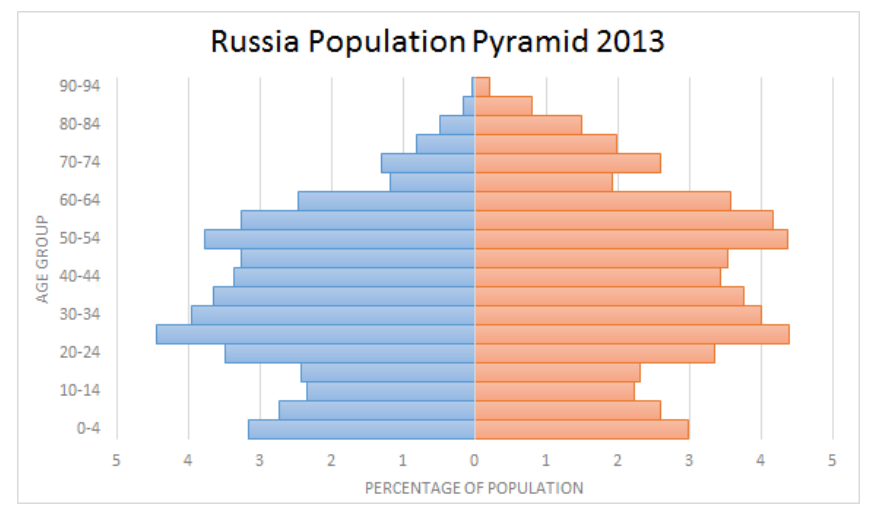

Figure 1. Russia's age structure is very similar to other east European countries, 2013

As generally in Russia there is gender imbalance in the Republic of Tatarstan which is presented in the following way: there is $53,8 \%$ of women and $46,2 \%$ of men in the whole population of the republic (The final results of 
All-Russian population census, 2013), which shows specific Russian problem. The continuous gender imbalance over the past decades can be explained by the number of reasons, such as the consequences of the World War 2, men loss in the more recent wars in frontiers. However, even in the peacetime the high level of the death-rate of the work age men can be observed. This is caused by the number of reasons, such as occupation on the hazardous and dangerous productions, alcoholism and drug addiction. Moreover, gender imbalance can be explained by the lower life expectancy for men than for women, and it's a steady trend.

Population distribution in the Republic of Tatarstan (according to the model perceived in Russian statistics 0-14 years - children, $15-59$ years - adults, 60 and more years - elder people) is the following: $16 \%$ of children, $66 \%$ of adults and $18 \%$ of elder people in January, 12012 (Natural population movement in municipal and city areas of the Republic of Tatarstan, 2013) According to the scale of the population ageing elaborated by G.Boge-Garnier and E.Rosset, the number of people aged from 60 years and more is minimum $12 \%$ in the old population. Age pyramid of old population has narrow base (number of children) and extended vertex (number of elder people), that shows that there are less children than older people. In the population of Tatarstan the part of the "third group"-elder people excess old age boundary in 1,5 times $(18 \%)$ what gives the evidence of regressive type of age structure and high level of population ageing, and consequently about the population loss. The combination of small proportion of children with substantial proportion of elder people in the age distribution points the high level of population ageing.

Vital rates of the population of the Republic of Tatarstan during the first decade of XXI century remained almost the same with low birth-rate $(9,4$ per mille in 2000) and high death-rate $(13,2$ per mille) with the natural population loss varied between 3,8 per mille in 2000 to 0,2 per mille in 2010 (Natural population movement in municipal and city areas of the Republic of Tatarstan, 2013).

In the Republic of Tatarstan the death-rate exceed the birth-rate since 1993. Since then steady trend of natural public loss is observed in the republic. The maximum losses were between the years 1999 and 2006, these years the republic was losing from 11 to 14 thousand of people every year. Only in 2011 natural population increasing took place in the republic after the year of 1993 the population increased to 4253 people and natural population increase in 2012 was 9426 people (Statistical data from the Civil registry offices, 2012).

Regarding the overall death rate Russia can be found at the same level as some African countries. The dynamics of overall coefficient of death rate from 2000 to 2010 shows the low level of variability, so in 2000 there were 15,3 per mille, in 201014,2 per mille with the maximum fluctuation of 1,9 per mille. In the Republic of Tatarstan the overall coefficient of the death rate is a little bit lower than in Russia, so it's 13,2 per mille in 2000 and 13,1 in 2010, however they are still higher than the overall birth rates. At the same time the gender differentiation can be observed in the following way: the death rate of men is higher than the death rate of women. The dynamics of overall coefficients of mortality in the gender prospective for 1000 people (Natural population movement in municipal and city areas of the Republic of Tatarstan, 2013) shows that there is a low level of variation with some decreasing after 2010. However, the death rates remain high, so the overall coefficient of the men death rate was 14,9 per mille in 2007 and 14,1 per mille in 2010; and the overall women death rate was lower, as 11,4 per mille in 2007 and 11,0 per mille in 2010. Differentiation of the death rate according to the type of settlement can also be observed, so the level of the death rate is higher in rural area than in the city area. Generally it was caused by the high level of starting (1990) death rate in the republic, 13,7 per mille in rural area and 8,5 per mille in city area.

While some death causes are clear and evident, others are hidden in the roots of social life. The following reasons can be mentioned above evident causes, such as: stress-producing as the consequent of socio-economical and political crisis, breakdown of habitual way of life in 1990s. At that time the death rate of working age men is particularly high, what is Russian peculiarity. Regarding the implicit reasons, deep stratification according to the economic position, marginalization of considerable part of society, that was particularly harmful for men, many of them have targeted to descending social mobility. Gender differentiation of death and sickness rates determined by the differences of social roles which are undertaken by men and women in the society. Men are more oriented to the social life and participation than women; that's why they (men) are more sensitive to radical social changes, it's more difficult to adapt themselves to the new life consequences. Gender differentiation of sickness and death rates is also caused by behavioral practices of men and women, by following or breaking regulations of healthy life-style (the lack of physical exercises, smoking, alcohol drinking and drug consumption etc. are more spread among men). The following reasons, such as: the difficulties with meeting life goals, limitation of opportunities for self realization, unemployment of some part of the population, and need to adapt in the difficult life situations, can be mentioned as implicit reasons of sickness and death rates. 
Among the death rate structure of Russian society, circulatory deceases can be noted as the first reason. Every year 1,3 million Russians are dying from cardiovascular diseases, this is $56 \%$ of the whole number of registered deaths. The other wide spread reason of deaths is oncologic disease, so every year 300 thousand of Russians are dying because of that. The sad statistics shows that every third Russian dies before the pension age. On behalf of academic E.Chazov, cardio diseases are caused by the hard psycho-social conditions, such as crisis in economics, politics (Russia is at the same level as some of the African countries..., 2013).

Table 2. Dynamics of circylatory disease and tutor in Russia

\begin{tabular}{lllllll}
\hline & 2007 & 2008 & 2009 & 2010 & 2011 & 2012 \\
\hline Circulatory disease (\%) & 62,0 & 62,8 & 62,8 & 65,0 & 59,0 & 53,8 \\
Tumor (\%) & 13,5 & 13,0 & 14,5 & 13,0 & 14,5 & 14,3 \\
\hline
\end{tabular}

The processes occurring in the population of the Republic of Tatarstan are generally similar to the Russian. Trends in death rate caused by the two most common causes, such as cardiovascular diseases and cancer, shows low differences of Russian and Tatarstan.

The analysis of the statistical data obtained during the All-Russian population census in the Republic of Tatarstan as well as the analysis of current statistical data in dynamics, shows that the main causes of death rate in the republic is death from circulatory diseases, and this is a stable trend, the death rate caused by these reasons remains high for many years. At the same time, $30 \%$ of deaths from diseases of the circulatory system accounted for the residents of the city of Kazan. Another common disease is cancer, claiming the lives of about $15 \%$ of the population. These stark statistics show that the decline in mortality from these diseases is problematic.

Presidential Decree dated October 9, 2007 N1351 adopted the concept of demographic policy of the Russian Federation for the period up to 2025 , which includes measures of economic support for young families and childbearing. Probably, the first results of these measures have affect to the demographic behavior of the population of the republic.

\section{Results}

The situation in the republic in terms of population relatively favorable - its growth is observed in the general population, but the dynamics of the population is ambiguous in some localities there is an increase of the population, in others - the decline. In general, the population of Tatarstan is increasing in the following ways, such as: firstly, due to migrants: an increase of 7.2 thousand for the inter-census period (2002 to 2010) and then, beginning from 2011 natural increase of population was also observed. The apparent change of the configuration of "Russian Cross" ("Russkiy crest") can be observed only in some localities of the republic such as the following ones: in the urban districts of Kazan and Naberezhnye Chelny, and also in the following municipal areas, Almetyevsk, Baltasi, Elabuzhsky, Kukmorsky, Nizhnekamsk, Sabinsky Tukaevsk. By the end of 2012, the structure of the newborn in the republic is the following: there is $47 \%$ of the first-born, $40 \%$ - the second child, $10 \%$ - third, $3 \%$ - the fourth and more. If we compare with 2007, the date of the commencement of the concept of the demographic development of the Republic of Tatarstan, including government programs of support for families with two and more children, the number of families with two and more children increased in almost a third more than in the beginning (Statistical data from the Civil registry offices, 2013).These data demonstrate the effectiveness of the population policy in the republic.

\section{Conclusion}

Analyzing the statistical data it can be stated that the demographic situation is still not very promising in the Republic of Tatarstan, as well as in Russia. Overall death rates are a little bit lower on the Republic of Tatarstan than in Russia, however the death rates are higher than the birth rates in the whole period under review and only from 2011 the birth rate is higher than the death rate. These data in complex approach characterize the narrowed mode of reproduction. Ambiguity and instability of positive dynamics in the Republic of Tatarstan, as well as in Russia as a whole, is largely determined by the unstable socio-economic situation, depressed position of some settlements, the remaining low level of life of a particular segment of the population, unemployment, lack of opportunities of self-realization, and finally, the inefficiency of many social programs. Thus, even if there are some positive trends in birth and death rates and rates of natural population growth, it's too early to state the breakdown. The time will show whether it's sustainable trend or no. 


\section{Acknowledgments}

The work was funded by the subsidy allocated to Kazan Federal University for the state assignment in the sphere of scientific activities.

\section{References}

Bessarabova, A. (2012). Russia has the long way to go to reach demographic records. Retrieved May 25, 2014, from http://mirnov.ru/arhiv/mn824/mn/02-2.php

Demographic crisis. (2013). Why the population of Tatarstan is increasing due to the migration? Retrieved May 3, 2014, from http://www.tatcenter.ru/online/39/

Natural population movement in municipal and city areas of the Republic of Tatarstan (statistical bulletin). Territorial organization of the Federal service for National Statistics in the Republic of Tatarstan. (2012). Retrieved May 3, 2014, from http://www.tatstat.gks.ru/wps/wcm/connect

Russia is at the same level as some of the African countries, according to the death rate. Retrieved May 12, 2014, from http://www.vitaminov.net/rus-news-0-0-18410.html

Russian Demography. Federal Agency for state statistics. Retrieved June 9, 2014, from http://www.gks.ru/

Russia's Age Structure Is Very Similar To Other East European Countries. Retrieved June 3, 2014, from http://www.forbes.com/sites/markadomanis/2013/07/09/russias-age-structure-is-very-similar-to-other-east-e uropean-countries/

Socio-economic state of the Republic of Tatarstan. Complex informational and analytical report. Retrieved June 7, 2013, from http://www.tatstat.gks.ru/wps/wcm/connect

Statistical bulletin of the Republic of Tatarstan, 2008. Retrieved June 7, 2014, from http://www.tatstat.ru/public/ ElectronLibrary/Forms/AllItems.aspx

Statistical bulletin of the Republic of Tatarstan, 2013. Retrieved June 7, 2014, from http://www.tatstat.ru/public/ ElectronLibrary/Forms/AllItems.aspx

Statistical data from the Civil registry offices. General register office of the acts of civil status of the Cabinet of Ministry of the Republic of Tatarstan. Retrieved June 3, 2014, from https://www.google.fr/url?sa= $\mathrm{t} \& \mathrm{rct}=\mathrm{j} \& \mathrm{q}=\& \mathrm{esrc}=\mathrm{s} \&$ source $=$ web $\& \mathrm{~cd}=1 \& \mathrm{ved}=0 \mathrm{CCIQFjAA} \& u r l=\mathrm{http} \% 3 \mathrm{~A} \% 2 \mathrm{~F} \% 2 \mathrm{Fzags} . \operatorname{tatarstan} . \mathrm{ru} \% 2 \mathrm{Fr}$ us\%2Ffile\%2Fpub\%2Fpub_226818.pptx\&ei=XrYbVI-7JsfMyAOw3ICACw\&usg=AFQjCNEPvEk6zy7Ci $4 \mathrm{uMw}$ hNNvZUtSK46Tg

The final results of All-Russian population census 2010. Federal service of National Statistics in the Republic of Tatarstan. Retrieved April 25, 2014, from http://www.gks.ru/

\section{Note}

Note 1. The Republic of Tatarstan is situated in the middle of Russian Federation, in the East-European plain, at the confluence of Volga and Kama rivers. It covers 67836 square kilometers. The capital is Kazan. The region has the administrative and territorial division, such as the following: 43 municipal areas and 2 city districts Kazan and Naberezhnye Chelny. The number of population in the Republic of Tatarstan is 3803.2 thousand people (2012), including $53,2 \%$ of Tatars and $39,7 \%$ of Russians (2010 census of enumeration). Regarding economy, Gross Regional Product of the Republic of Tatarstan is 1415.0 billion rubles (2012 which is 105,5\% to 2011).

\section{Copyrights}

Copyright for this article is retained by the author(s), with first publication rights granted to the journal.

This is an open-access article distributed under the terms and conditions of the Creative Commons Attribution license (http://creativecommons.org/licenses/by/3.0/). 